\title{
Female Leadership as a Moderator on Human Resource Flexibility Affecting Firm Performance
}

\author{
Tyse Adwoa Asantewaa Acquah, Hui Xing* \\ School of Economics and Management, Hebei University of Technology, Tianjin, China \\ Email address: \\ tyseacquah@yahoo.com (T. A. A. Acquah),xingteam@126.com(Hui Xing) \\ ${ }^{*}$ Corresponding author
}

\section{To cite this article:}

Tyse Adwoa Asantewaa Acquah, Hui Xing. Female Leadership as a Moderator on Human Resource Flexibility Affecting Firm Performance. Journal of Human Resource Management. Vol. 9, No. 3, 2021, pp. 94-101. doi: 10.11648/j.jhrm.20210903.16

Received: August 28, 2021; Accepted: September 22, 2021; Published: September 29, 2021

\begin{abstract}
From the works of scholars in the field of Human Resource Management (HRM), conceptualization establishes that Human Resource (HR) Flexibility is important in a firm's sustainability. Skill flexibility, behavior flexibility, and HR practice flexibility have been acknowledged in the literature as the dimensions of HR flexibility with a significant impact on performance for the sustainability of firms in today's turbulent environments. This paper explores the moderation role of Female Leadership (FL) between HR Flexibility (HRF) and Firm Performance (FP). Furthermore, the authors also investigate the individual effect of skill, behavior, and HR practice flexibility moderated interaction of Female leadership on performance of firms. Data was collected using a questionnaire as an instrument from $202 \mathrm{HR}$ managers in Ghana. Using correlation and regression analyses to test for the interaction modeling, the hypotheses of the study are tested. The results confirm a moderation of Female leadership on the relationship between HR Flexibility and firm performance. The findings revealed that there is a positive effect of HRF on firm performance (HR-related and Market-related outcomes) which is reinforced by the moderator. The results reached in this paper contribute to the literature of HR flexibility on firm performance. The paper brings insight to the strategic role of Female leadership, so far as flexibility is concerned for higher organizational capability.
\end{abstract}

Keywords: HR Flexibility, Firm Performance, Female Leadership

\section{Introduction}

Every firm works towards its performance and to be leading in whatever industry it finds itself. Human Resource Flexibility (HRF) is a key gradient in the achievement of excellence in the operations of a firm which helps to strategically anticipate and respond promptly to the changes that are surrounded by the business environment [1-3]. Among developing countries, Ghana is one of the fastest-growing economies in Africa with industrial development in the various sectors being key in the acceleration and sustainability of this economic growth, with the aim of contributing to changing the country's current income level of lower middle income as described by the World Bank with a GDP of $\$ 66.984$ billion as at 2019. The various firms in different sectors in the economy are surrounded by growing competition, waning operational proceeds, dismissals, enterprise closures and merges, as well as an ever-high-level degree of uncertainties, organizations need to possess the ability to familiarize to instabilities in demand and to changes in their environment in order to survive or attain success.

Some scholars [4] argue that that HR flexibility is likely to prevail over its advantages therefore in competitive environs, HR flexibility is not needed because it affects the efficiency and financial performances of firms due to the cost of inculcating flexibility in the firm. Nevertheless, flexibility in the workplace during the past two decades has introduced optimistic changes in employees as well as organizational performance and productivity. The concept of flexibility has established freedom for businesses to think, experience, and act to achieve organizational targets and objectives without pushing considerable stress on reaching only the financial goals of the organization as researchers have proposed it as a 
precious capability [5-7].

However, the contributing role of HR flexibility to the preservation of organizational efficiency in turbulent environs has not been sufficiently addressed. This is due to some ambiguously drawn inferences on the causal mechanism and moderating factors influencing HR flexibility and Firm Performance (FP). There is therefore the need to evaluate how flexibility advances the performance of a firm as it has not been adequately researched empirically in Africa.

A study by Agyemang and colleagues shows that working-class women have not been participating as part of the board of directors in Ghana due to the companies not creating an enabling environment in their system of governance [8]. Contemporary studies have established that women are now crossing a milestone of a wide spectrum of activities in modern times. Conversely, leadership is not gender-specific, as it simply needs a person who influences and encourages the realization of a set of goals of a group of people. Not only can gender allinclusiveness in leadership concomitantly bring financial return but goes beyond it.

Hence, to confront the topic at hand and the call made by extant scholars to identify other variables to support the literature, this study explores the impacts of HR flexibility on firm performance. To bridge the existing HR flexibility-firm performance literature gap in Ghana, the study hopes to make important contributions to the literature. Further, the study seeks to conduct research considering a moderator effect: the impacts of female leadership on the HR flexibility of a firm and its performance. By this, we are going to focus on HR flexibility and its relatedness to the moderating variables at the firm level.

First, unravel how performance (HR-related performance and Market-related) is impacted across the dimensions of flexibility (skill, behavior, and HR practices) in today's uncertain business environment. Second, explores how female leadership affects the HR flexibility-firm performance relationship.

Figure 1 is the research conceptual model showing the moderating role of Female Leadership (moderator variable) on HR Flexibility (independent variable) and Firm Performance (dependent variable).

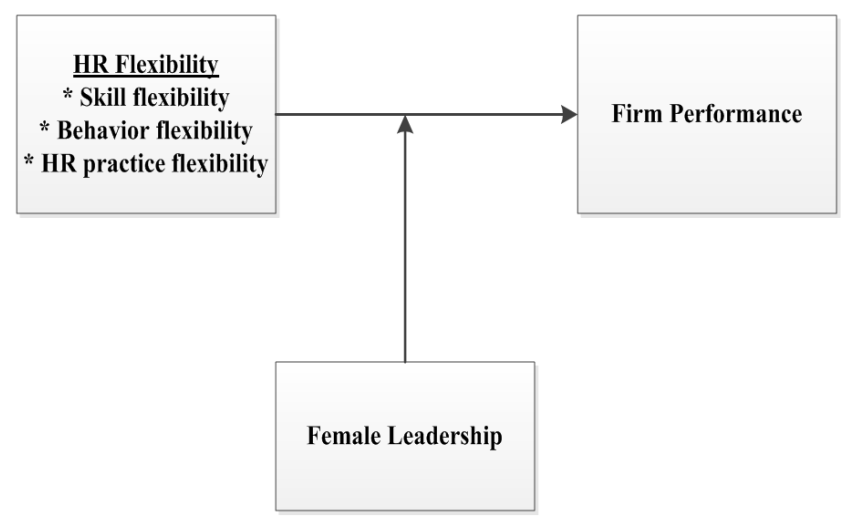

Figure 1. Conceptual Model.

\section{Literature and Hypothesis}

\subsection{Human Resource Flexibility and Firm Performance}

In the field of Human Resource Management, several scholars have desegregated the concept of flexibility to elaborate on how leaders of firms can succeed in the rapid and unpredictable change of events $[1,4,9-11]$. Flexibility is a firm's receptiveness to fluctuations and pressures surrounding the firm which makes them readily and effectually pursue the course of action to see these competitive changes $[4,13]$. Value is created from the skilled, motivated, and empowered employees who generate and deliver value which enables the firm to sell its goods and services right to stakeholders and shareholders [13]. Research has established that in a flexible work environment, the needs of both the employers and employees are met, making workplace flexibility a vital tool for retaining and engaging employees, and can subsequently help organizations to attain targeted goals [6].

Flexibility is regarded as an internal feature of a firm that consists of skill flexibility, behavior flexibility, and HR practice flexibility [10]. The measure of the outcome of a firm's functions and operations is firm performance. The performance of a firm is not only measured financially. The morale of employees, their retention, employee grievances, employment relations, development of new products, net profits of the firm, and sales or turnover are the indicators for Human Resource related and Market-related performance. Further research has indicated that employee skill, behavior, and HR practices are significantly associated with an index of firm financial performance and the general firm performance $[3,15,16]$.

Skill flexibility is the most important antecedent to behavior flexibility and is generated in two ways. Existing employees with broad varieties of skills and second, employing skilled personnel. Employees may have a variety of skills but being under-utilized to make way for opportunities for the firm. Firms that employ people or specialists with a variety of skills to provide the needed flexibility to meet changing demands. The skill flexibility that pertains to a particular firm could be difficult to imitate as obviously skills play a role in the flexibility of a firm.

An employee can be highly motived to act flexibly but lacks the required skills and knowledge to act accordingly. Employee competence developed through flexible HR skills, knowledge, attitude control, professionalism, and experience positively and significantly correlated with job satisfaction and firm performance [6]. Skill flexibility is a source of competitive advantage to a firm as different duties could be carried out to meet demands when the need arises.

Behavior flexibility is the extent to which employees can willingly switch to the contradicting change in situations by a change in the behavior script, rather than simply applying standard operations procedures [10]. Behavioral flexibility plays an important role for people who work in a particular firm. This is because it makes the firm capable of responding 
to the different demanding, dynamic, and competitive conditions; for the reason of running organizational roles successfully leading to competitiveness. Research concluded that behavioral flexibility is significantly correlated with HR flexibility and firm performance and negatively associated with organizational role stress [17].

HR practice flexibility is the extent to which a firm's HR practices can be quickly redeployed across various situations of a firm. Training and development, employee empowerment, employee communication, and participation, among others, are the features of HR practice flexibility. HR practice flexibility bring value. For instance, compensation plans for employees induce behavioral changes, as the compensation is based on how successful a firm can be in different situations and aids in the reconfiguration of the skills of the employees. Further reports are in agreement with the proof that all these flexible HR practices have a positive correlation with firm performance $[16,18]$. This flexibility is difficult to imitate through its responsiveness to turbulent environs a firm finds itself in a strategic consistent manner [15]. Hence, with the introduction and implementation of the various variables under HR practices with practical examples as training and development, and employee empowerment among others, these three dimensions of flexibility (skill, behavior, and HR practice flexibilities) merged will in turn impact positively on the performance of the firm. Thus, with the above argument, the hypothesis is:

Hypothesis 1. Human Resource Flexibility positively relates to firm performance.

Hypothesis 1a. Skill Flexibility positively relates to firm performance.

Hypothesis $1 \mathrm{~b}$. Behavior Flexibility positively relates to firm performance.

Hypothesis 1c. HR practice Flexibility positively relates to firm performance.

\subsection{Female Leadership as a Moderator}

Taking into account how necessary it is for firms to be performant, the need to be transparent, communal, relationoriented, nurturing, and ethically behaved is ideally unmistaken. Females in leadership positions are important to be internalized in a firm in order to see to the transformational goal to be implemented and survive in an organization [19]. This is because the aforementioned traits such as being nurturing and communal are dominant in females. There are technical aspects in every organization that needs adjustments to be made willingly and strategically in order to create an enabling environment to implement HR flexibility patterns.

Scholars have recommended that the feminine way of governance needs to be accentuated due to its participative and open communication nature [20]. There is a need for leadership to acclimate the feminine relational qualities, such as warmth, understanding, assertiveness, and sensitivity. The natural multitasking abilities that women play in their daily lives supplements their peculiar way of life. It enriches leadership skills of which provides them with an advantage in the work setting. This trait reinforces the flexibility dimensions as skill flexibility through inspiring multitasking, behavior flexibility by encouraging adjustment to situations in the workplace, and HR practice flexibility encouragement by the extent to which HR practices could be easily redeployed.

Women adjust more to change than men do, they are attentive to the development of the people they work with through listening and encouraging them to do things in a different but original way as they are ethical and inspirational [21]. Females are better facilitators of features such as being diverse in nature, transparent and democratic to facilitate firm flexibility [22]. Behavior flexibility is to adjust to conducts in different situations, the extent to which the present procedures for selecting, developing, motivating, and retaining employees can be applied to a wide range of environmental contexts [13, 22, 23]. Transformational female leaders have a persuasive behavior of motivating employees and developing their self-interest for the firm as the willing and differing switch of the routine manner (behavior flexibility) of employees in a firm [19].

Development of new skills from existing skills and the ability to efficiently use them is critical. Females are better collaborators of HR flexibility and firm performance. Projections are hence made that firms who are HR flexibility sensitive will better perform if females other than males are in leadership positions. Their nature influences behavioral scripts and skills as all responses received by the firm are duly reflected, enabling firms to prudently correspond with the available limited resources. Evidence from the study shows that females leadership influences performance and indicates that Cooperate Social Responsibility Disclosure in Ghana grows when females serve on the board $[22,8]$.

Again, a study probing 239 microfinance institutions in 73 countries globally on the link between female leadership, firm performance, and corporate governance in a global panel revealed that female CEOs and chairpersons of boards are positively related to microfinance institutions performance [24]. Despite the shortcomings faced with females being in leadership positions, this role informs others about exceptional skills when organizational competency is achieved through its flexibility practices in light of leading to performance. It is hypothesized that:

H2. Females Leadership reinforces the impact of Skill flexibility on firm performance.

H2a. Females Leadership reinforces the impact of Behavior flexibility on firm performance.

H2b. Females Leadership reinforces the impact of HR practice flexibility on firm performance.

\section{Methodology}

\subsection{Sample and Research Design}

The study employed the quantitative research approach 
conducting a questionnaire-based survey in relation to the literature reviewed. The population of the study included 202 HR Managers spread across Ghana. Responses showed that $59 \%$ were males and the remaining $41 \%$ were females with educational levels of $51 \%$ being Bachelor degree holders, 48.5\% being Master's degree holders and, 5\% being Ph.D. holders. 35\% of the respondents were from manufacturing and the remaining $65 \%$ from the service industry with $86 \%$ of the sample size having work experience of zero to ten years and $14 \%$ having worked for more than ten years. Small, medium and, large firm sizes recorded $23 \%, 64 \%$ and, $13 \%$ respectively. In addition, $52 \%$ of the respondents came from the public sector firms, $42 \%$ from private and, the remaining $6 \%$ from public-private firms.

\subsection{Software and Data Analysis}

The data was analyzed using SPSS version 25, AMOS version 26.0, and Andrew F Hayes Process Macro version 3.5. Analysis was initially conducted in SPSS to ensure that the data was suitable. Exploratory factor analysis (EFA) and a model fitness were conducted. Confirmatory factor analysis (CFA) in AMOS was used to extract the number of latent factors and verify the measurement structure of all the attributes respectively. The functions of chi-square, degrees of freedom (df), comparative fit index (CFI), normed fit index (NFI), the goodness of fit index (GFI), adjusted goodness of fit index (AGFI), incremental fit index (IFL), parsimonious comparative fit index (PCFI), and the root mean squared error of approximation (RMSEA) are reported. Fit indices were in the acceptable range agreed by various scholars [25]. The previous study recommends that Cronbach's alphas greater than or equal to 0.7 are considered acceptable [26]. To reflect a satisfactory fit, the fit indices values are shown for the CFA. A regression analysis was conducted to test moderation through the interaction term.

\subsection{Measures}

Firm performance - a comparative assessment of firm performance was adapted [12]. The performance objective indicators made up of Human Resource related (morale of employees, retention of employees, and employment relations) and Market-related (were sales/turnover, net profit, and new products development) indicators were highly correlated to the perceived measure of firm performance.

HR Flexibility - HR flexibility measurement was adapted $[7,14]$.

Moderator variable - Female in leadership positions which is a construct of five items was adapted to assess leadership [27].

Control variables - three control variables were used: firm size (small, medium, or large), industry type (manufacturing/service), and firm nature (governmentowned, private owned, and government-private owned).

\section{Results and Discussion}

Exploratory factor analysis followed by confirmatory factor analysis was conducted before testing for the hypothesis to assess if the response were distinguished by respondents. A measurement fit conducted had a chi-square value of 320.393 with df 110 ( $p<0.05)$. Reliability, which shows the internal consistency, denotes the homogeneity of the items that make up the measurement scales. A stronger relation between latent constructs shows when the correlation between inter items is also strong. For this reason, a reliability test was carried out in Table 1 . Cronbach values were all above 0.7 signifying the internal consistency.

Table 2 shows the mean and standard deviations among projected parameters of the research model. The goodness of fit meets the accepted recommended levels in Table 3. The parameters show that HR Flexibility and its dimensions are positively correlated to each other and to firm performance as expected.

Table 1. Scale measurement

\begin{tabular}{|c|c|c|c|c|c|}
\hline Variables & & No. of Items & Mean & SD & Cronbach's alpha $(\alpha)$ \\
\hline \multirow[t]{4}{*}{ HR Flexibility } & Skill flexibility (SF) & 5 & 9.80 & 2.584 & .834 \\
\hline & Behavior flexibility (BF) & 5 & 10.81 & 2.842 & .751 \\
\hline & HR practice flexibility (HRPF) & 5 & 11.30 & 3.016 & .802 \\
\hline & Total & 15 & 31.91 & 7.450 & .855 \\
\hline \multirow[t]{7}{*}{ Firm Performance } & FP1 & 1 & 1.91 & .723 & .734 \\
\hline & FP2 & 1 & 2.23 & .811 & .751 \\
\hline & FP3 & 1 & 2.03 & .749 & .754 \\
\hline & FP4 & 1 & 2.14 & .805 & .756 \\
\hline & FP5 & 1 & 2.09 & .723 & .761 \\
\hline & FP6 & 1 & 2.44 & .766 & .771 \\
\hline & Total & 6 & 12.85 & 3.188 & .787 \\
\hline \multirow[t]{6}{*}{ Female Leadership } & FL1 & 1 & 2.23 & .998 & .766 \\
\hline & FL2 & 1 & 2.13 & .812 & .746 \\
\hline & FL3 & 1 & 2.18 & .829 & .735 \\
\hline & FL4 & 1 & 2.32 & .863 & .761 \\
\hline & FL5 & 1 & 2.45 & .972 & .737 \\
\hline & Total & 5 & 11.31 & 3.306 & .789 \\
\hline
\end{tabular}


Table 2. Descriptive statistics, mean and standard deviation.

\begin{tabular}{|c|c|c|c|c|c|c|c|c|c|c|c|c|c|}
\hline Item & Mean & SD & HRF & SF & BF & HRPF & FP & HRRP & MRP & FL & Industry & $\begin{array}{l}\text { Firm } \\
\text { size }\end{array}$ & $\begin{array}{l}\text { Firm } \\
\text { nature }\end{array}$ \\
\hline HRF & 31.9 & 7.45 & 1 & & & & & & & & & & \\
\hline SF & 9.80 & 2.58 & 0.850 & 1 & & & & & & & & & \\
\hline $\mathrm{BF}$ & 10.8 & 2.84 & 0.905 & 0.673 & 1 & & & & & & & & \\
\hline HRPF & 11.30 & 3.02 & 0.889 & 0.609 & 0.716 & 1 & & & & & & & \\
\hline FP & 12.9 & 3.19 & 0.577 & 0.472 & 0.488 & 0.562 & 1 & & & & & & \\
\hline HRRP & 6.17 & 1.87 & 0.540 & 0.450 & 0.437 & 0.536 & 0.881 & 1 & & & & & \\
\hline MRP & 6.67 & 1.78 & 0.468 & 0.374 & 0.416 & 0.445 & 0.868 & 0.530 & 1 & & & & \\
\hline FL & 11.31 & 3.31 & 0.516 & 0.351 & 0.516 & 0.488 & 0.465 & 0.376 & 0.440 & 1 & & & \\
\hline Industry & 1.65 & 0.48 & 0.078 & 0.080 & 0.133 & -.002 & 0.066 & 0.091 & 0.022 & -.012 & & & \\
\hline Firm size & 1.90 & 0.59 & 0.111 & 0.095 & 0.131 & 0.070 & 0.032 & 0.034 & 0.021 & 0.082 & 0.405 & & \\
\hline Firm nature & 1.54 & 0.61 & -.004 & -.026 & -.043 & -.043 & 0.020 & 0.065 & -.032 & -.001 & 0.248 & 0.492 & \\
\hline
\end{tabular}

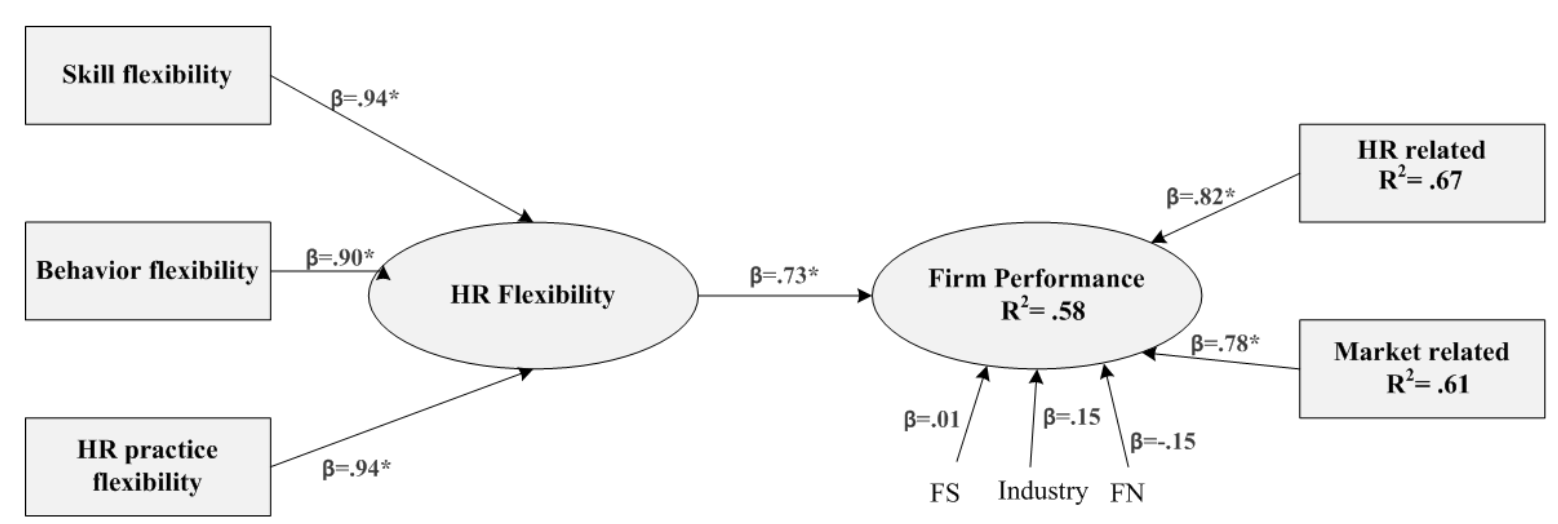

Note: FS - Firm size, FN - Firm nature * $p<0.05$

Figure 2. Structural analysis model.

Table 3. Goodness of fit indices.

\begin{tabular}{llllllllll}
\hline Estimated model & $\mathbf{x}^{\mathbf{2}}$ & $\mathbf{d f}$ & $\mathbf{R M E S A}$ & NFI & GFI & AGFI & IFI & CFI & PCFI \\
\hline Model fit values & 320.393 & 110.00 & 0.09 & 0.74 & 0.85 & 0.80 & 0.81 & 0.81 & 0.65 \\
Recommended acceptance level & & Lower than 0.1 & Close to 0.9 & Close to 0.9 & Close to 0.9 & Close to 0.9 & Close to 0.9 & above 0.5 \\
\hline
\end{tabular}

With postulations from hypotheses $1,1 \mathrm{a}, 1 \mathrm{~b}$ and, 1c, 1 (r $=.73, \mathrm{p}=0.05), 1 \mathrm{a}(\mathrm{r}=.94, \mathrm{p}=0.05), 1 \mathrm{~b}(\mathrm{r}=.90, \mathrm{p}=0.05)$ and $1 \mathrm{c}(\mathrm{r}=.94, \mathrm{p}=0.05)$. Therefore, H1a, H1b, H1c and,
H1d are supported. Behavior flexibility was the least correlated among the magnitude of correlation between the dimensions to performance.

Table 4. Interaction term summary.

\begin{tabular}{|c|c|c|c|c|c|c|c|c|c|}
\hline Moderation Model & $\begin{array}{l}\text { Independent variable } \\
(\mathrm{X})\end{array}$ & $\begin{array}{l}\text { Beta } \\
\text { coefficient }\end{array}$ & $\mathbf{R}^{2}$ & $\begin{array}{l}\mathbf{R}^{2}-\text { chng } \\
(\mathbf{X} * \mathbf{W})\end{array}$ & se & $\mathbf{t}$ & $\mathbf{p}$ & LLCI & ULCI \\
\hline SF, FL, SF_FL, FP & SF & .0651 & .6076 & .0439 & .0175 & 3.7140 & .0003 & .0305 & .0997 \\
\hline BF, FL, BF_FL, FP & $\mathrm{BF}$ & .0418 & .5792 & .0353 & .0129 & 3.2447 & .0014 & .0164 & .0673 \\
\hline HRPF, FL, HRPF_FL, FP & HRPF & .0318 & .6212 & .0225 & .0118 & 2.6941 & .0077 & .0085 & .0552 \\
\hline
\end{tabular}

Examination of the interaction term shows the enhancing effects that as female leadership increases, the firm performance that is impacted through skill, behavior, and HR practice flexibilities increases respectively in Tables 5, 6, and 7 conditional effect indices.

Table 5. Conditional effect of FL on SF and FP.

\begin{tabular}{|c|c|c|c|c|c|c|}
\hline \multicolumn{7}{|c|}{ Focal predict: Skill flexibility } \\
\hline \multicolumn{7}{|c|}{ Moderator variable: Female Leadership } \\
\hline \multicolumn{7}{|c|}{ Conditional effects of the focal predictor at the values of the moderator } \\
\hline 9.000 & .2526 & .0891 & 2.8367 & .0050 & .0770 & .4282 \\
\hline 11.000 & .3829 & .0757 & 5.0602 & .0000 & .2337 & .5321 \\
\hline 15.000 & 6433 & .0932 & 6.9006 & .0000 & .4595 & .8272 \\
\hline
\end{tabular}


Tables 4, 5, 6 and, 7 show the statistics of the structural equation of the moderator effect done using Andrew F. Hayes Process Macro version 3.5. The indices of the interaction term from Tables 4 and 5 show that the $p$ value is significant and zero does not exist in the lower and upper-level confidence interval. In addition, there is an $\mathrm{R}$ square change. The conditional effects show that the relationship is moderated at the lowest value at the $16^{\text {th }}$ percent. At its $50^{\text {th }}$ percentile, the conditional effect of Female leadership as a moderator between Skill flexibility and performance is medium. At the $84^{\text {th }}$ percentile, the conditional effect is at its maximum level of $(\beta=.6433, p>0.05)$ between Skill flexibility and Firm performance. $\mathrm{H} 2$ is supported.

Table 6. Conditional effect of FL on BF and FP.

\begin{tabular}{|c|c|c|c|c|c|c|}
\hline \multicolumn{7}{|c|}{ Focal predict: Behavior flexibility } \\
\hline \multicolumn{7}{|c|}{ Moderator variable: Female Leadership } \\
\hline \multicolumn{7}{|c|}{ Conditional effects of the focal predictor at the values of the moderator } \\
\hline FL & Effect & se & $\mathbf{t}$ & $\mathbf{p}$ & LLCI & ULCI \\
\hline 9.000 & .2027 & .0932 & 2.1742 & .0309 & .0188 & .3865 \\
\hline 11.000 & .2864 & .0810 & 3.5358 & .0005 & .1266 & .4461 \\
\hline 15.000 & .4537 & .0793 & 5.7211 & .0000 & .2973 & .6101 \\
\hline
\end{tabular}

The $\mathrm{p}$ value from Table 4 depicts the non-existence of zero in the lower and upper-level confidence interval. With a continual increase $(\beta=.2027, p>0.05 ; \beta=.2864, p>0.05 ; \beta$ $=.4537, \mathrm{p}>0.05)$ in the conditional effect of the moderator variable (Female Leadership) at the low, medium and maximum levels of percentiles of $16^{\text {th }}, 50^{\text {th }}$ and $84^{\text {th }}$ respectively. These results support the postulation that the relationship between Behavior flexibility and Firm performance is stronger in the presence of Female leadership in Table 6. $\mathrm{H} 2 \mathrm{a}$ is supported.

Table 7. Conditional effect of FL on HRPF and FP.

Focal predict: HR practice flexibility

Moderator variable: Female Leadership

Conditional effects of the focal predictor at the values of the moderator

\begin{tabular}{lllllll}
\hline FL & Effect & se & t & p & LLCI & ULCI \\
\hline 9.000 & .3454 & .0806 & 4.2878 & .0000 & .1866 & .5043 \\
11.000 & .4091 & .0705 & 5.8055 & .0000 & .2701 & .5481 \\
15.000 & .5365 & .0726 & 7.3894 & .0000 & .3933 & .6796 \\
\hline
\end{tabular}

Tables 4 and 7 shows the results of moderation between the dependent and independent variable. Zero does not exist in the confidence levels. The beta of the dependent and independent variable is increased from the low to the maximum conditional effect $(\beta=.3454$ to $\beta=.5365, \mathrm{p}>.05$ ) of the moderator. The HR practice flexibility and firm performance relationship are reinforced in the presence of the moderator. $\mathrm{H} 2 \mathrm{~b}$ is supported.

Viewing from a theoretical point, the research presented validates the need for a broadening of contextual factors regarding HR Flexibility-firm performance relationship, with a focus on the causal mechanism embedded in this relation. The contribution that this study makes to the existing literature is the results drawn from the study as Female leadership moderates HR Flexibility on the firm's HR-related (morale of employees, retention of employees, employment relations) and Market-related (sales/turnover, net profit, new products development) performance of firms in the dynamic business environments. In the HR flexibility study, this novelty allows for better understanding. This study offers a comprehensive view of flexibilities simultaneously. Our findings are consistent with other studies [1, 14] as a key ingredient of competitive advantage.

Unlike other studies, this paper analyses skill, behavior, and HR flexibilities, which enables us to assess each of the flexibilities dimensions' contribution to the performance measure. Through this study, knowledge is broadened on the impact of flexibility on other performance measures other than financial only.

The constituents were studied through testing for the interaction term of female leadership and the three dimensions of flexibility through the interaction model in the regression analysis. We found that skill flexibility, behavior flexibility and, HR practice flexibility had positive relation to performance. Female leadership moderates HR practices higher than skill flexibility and behavior flexibility. When female leadership moderates the HR flexibility and firm performance relationship, the advantage it gives to the firm becomes higher. The Goodness-of-fit showed a good fit and the structural model showed strong and significant path loading for the important linkages under consideration. A significant moderator effect of Female leadership is established. From the descriptive statistics, it is found that HR Flexibility impacts the performance of the firm.

\section{Conclusion}

The results show the moderation ability of Female leadership as a reinforcement to the HRF and Firm performance relationship. A stream of research depicts the Human Resource Flexibility-firm performance relation was tested and established around the world. Global competition facing organizations in today's world to be performant and thrive is imperative to employ HR Flexibility as a strategic tool [6]. These results underscore the importance of HR flexibility. HR flexibility brings out diversity and uniqueness, shared duty or guidance, robustness, among others within employees [1]. It is unmistakable that Human Resource flexibility activities have a relevant impact on firm performance, as competitors cannot easily imitate it. It is worth noticing that critical and strategic thinking, genuine concern for others' well-being and development, empowerment, delegation, and development of leadership potentials of firms are well-fortified when females are in leadership positions. Human resource flexibility certainly betters' skills, alters behavior, and quickly reorganizes HR practice for the forward movement of firms. It is important for firms to encourage the activities of Human Resource flexibility by creating a supportive environment such as allowing for Female leadership for its functioning leading to the performance of a firm. 


\subsection{Research Implication}

This study provides bases of motivation for managers to analyze and expand their HR flexibility system, taking advantage of the different combinations of the dimensions of flexibility with females in leadership positions for operative utilization of human capital in their organizations base on today's unanticipated business environment. The study provides a conceptual framework, creating the basis for future researchers to further study. In practice, for the attainment of better performance and dominance in an industry, managers of firms need to foster HR flexibility system with female leadership roles. A firms' development of new products, net profits, sales, retention of its employees, and their employment relation as indicators of performance are improved. As shown in the research findings, the creation of such an environment coupled with emphasizing the HR practices, skill, and behavior flexibilities of the firm yields an advantageous end.

\subsection{Research Limitation}

Data were derived from questionnaires distributed and collected from managers of different industries in Ghana. Future research on this can be done in other countries or continents with specifics on one particular industry. The possibility of a social desirability bias is suggested to be a limitation in this study [23]. Though guaranteeing the anonymity of the data collected during the survey, managers may over-report desirable firm profiles, in particular concerning female leadership. Because social desirability bias may affect the validity of survey research findings, future studies should initiate techniques to prevent or reduce this bias. We specifically believe it is important to attach substantial concern to this matter.

Further studies could consider both genders to draw conclusions to contribute to the literature. One rater (HR managers) is used in this study. Following studies could use two or more, for example, the HR manager and the head of units or departments of the firm. Hence the need to perform multilevel studies to validate conclusions drawn on the current study.

Other classifications or theories [9] under HR flexibility could be studied together with other moderating variables used to determine other performance indicators such as employee outcome (e.g. job satisfaction, job performance). Other conceptual cultural traits aside from developmental culture could be considered.

\section{Funding}

The National Social Science Foundation of China "Research on the Mechanism of Open Innovation Driving Manufacturing Transformation and Upgrading" (18BJY027), host: Xing Hui.

\section{Acknowledgements}

The authors would like to extend thanks to the National
Social Science Foundation of China for funding support.

\section{References}

[1] Chandra, S., Manoj, P. \& Vishal, V. (2016). A Study of HR Flexibility and Firm Performance: A Perspective from IT Industry. Global Journal of Flexible Systems Management, 17, 57-75. doi 10.1007/s40171-015-0120-2.

[2] Owino, O. J. \& Francis, K. (2019). Organizational Culture and Performance: Evidence from Microfinance Institutions in Kenya. SAGE Open, 9 (1): 1-11.

[3] Sabuharia, R., Sudirob, A., Dodi, W. I. \& Rahayu, M. (2020). The effects of human resource flexibility, employee competency, organizational culture adaptation and job satisfaction on employee performance. Management Science Letters, 10 (8): 1777-1786.

[4] Way, S. A., Wright, P. M., Tracey, J. B. \& Isnard, J. F. (2018) HR flexibility: precursors and the contingent impact on firm financial performance. Human Resource Management, 57 (2): 567-582.

[5] Maria-Jose, V-J., Angel, M-S., Manuela, P-P. \& Silvia, A. (2014). How environmental changes and cooperation moderate labor flexibility and firm performance. European Journal of Marketing, 43 (6): 915-936.

[6] Pradhan, R. K., Gita, K. I. \& Kumar, U. (2017). Human resource flexibility and organizational effectiveness: mediating role of organizational citizenship behavior. International Journal of Human Resources Development and Management, 17 (3/4): 282-300.

[7] Mercedes, U-G., Enrique, C-C., Bartolome, M-L. \& Patrocinio, Z-S. (2017). Human resource flexibility and performance in the hotel industry: The role of organizational ambidexterity. Personnel Review, 46 (4): 824-846.

[8] Agyemang, A. O., Kong, Y., Ayamba, E. C. \& Vincent, K. T. (2017). Impact of Gender Diversity on Corporate Social Responsibility Disclosure (CSRD) in Ghana. International Journal of Economics Review \& Business Research, 4 (2): 124.

[9] Sanchez, R. (1995). Strategic flexibility in product competition. Strategic Management Journal, 16 (1): 135-159.

[10] Wright, P. M. \& Snell, S. A. (1999). Toward a unifying framework for exploring fit and flexibility in strategic human resource management. Academy of Management Review, 23, 756-772.

[11] Tracey, J. B. (2012). A contextual, flexibility-based model of the HR-firm performance relationship. Management Decision, 50 (5): 909-924.

[12] Hang-Yue Ngo \& Raymond Loi. (2008). Human resource flexibility, organizational culture and firm performance: an investigation of multinational firms in Hong Kong. The International Journal of Human Resource Management, 19 (9): 1654-1666.

[13] Hayton, J. (2006). Human capital management practices and performance in small and medium-sized enterprises: a conceptual framework. In: Tansky, J. \& Heneman, R. (Eds.) (2006). Human Resource Strategies for the High Growth Entrepreneurial Firm, Information Age, Press, Greenwich. 
[14] Sumita, K. \& Sett, P. K. (2010). Environmental dynamism, human resource flexibility, and firm performance: analysis of a multi-level causal model. The International Journal of Human Resource Management, 21 (8): 1173-1206.

[15] Bhattacharya, M., Donald, E. \& Harold, D. (2015). The Effects of Flexibility in Employee Skills, Employee Behaviors, and Human Resource Practices on Firm Performance. Journal of Management, 31 (4): 622-640.

[16] Tuan, L. T. (2019). HR flexibility and job crafting in public organizations: The roles of knowledge sharing and public service motivation. Group \& Organization Management, 44 (3): $549-577$

[17] Connell, J. (2018). Global Value Chains, Flexibility and Sustainability. In: Agarwal, R. \& Sushil, Dhir, S. (Eds.) (2018). Flexible Systems Management Springer, Singapore.

[18] Nandakumar, M. K. (2014). In: Jharkharia, S. \& Nair, A. (Eds.) (2014). Organizational Flexibility and Competitiveness. Flexible Systems Management, Springer, New Delhi.

[19] Raluca-Elena, H. (2015). Impact of Leadership on Organizational Performance. Romanian Foundation for Business Intelligence, 3 (7): 289-294.

[20] Paustian-Underdahl, S. C., Walker, L. S. \& Woehr, D. J. (2014). Gender and Perceptions of Leadership Effectiveness: A Meta-Analysis of Contextual Moderators. Journal of Applied Psychology, 99 (6): 1129-1145.
[21] Riggio, R. E. (2010). Why women may be better leaders than men. Available at: www.psychologytoday.com/blog/wiredsuccess/201212/why-men (accessed on 30 July 2020).

[22] Lin, X., Xin, L., Zhao, C. \& Wei, X. (2017). Strategic flexibility, innovative HR practices, and firm performance; A moderated mediation model. Personnel Review, 46 (7): 13351357.

[23] Beltran-Martin, I. \& Roca-Puig, V. (2013). Promoting Employee Flexibility Through HR Practices. Wiley Periodicals, Inc, 52 (5): 645-674.

[24] Reidar, O. S., Bert, D' E. \& Roy, M. (2014). Female leadership, performance, and governance in microfinance institutions. Journal of Banking \& Finance, 42 (1): 60-75.

[25] Schumacker, R. \& Lomax, R. G. (1996). A Beginner's Guide to Structural Equation Modelling. Journal of the Royal Statistical Society, 47 (2).

[26] George, D. \& Mallery, P. (2003). Using SPSS for Windows Step by Step: A Simple Guide and Reference. 4th Edition. London: Pearson Education.

[27] Alimo-Metcalfe, B. \& Alban-Metcalfe, J. (2000). A New Approach to Assessing Transformational Leadership. Section and Development Review, 16 (5): 15-17. 